\title{
Deformation and recrystallization mechanisms and their influence on the microstructure development of rare earth containing magnesium sheets
}

\author{
Changwan $\mathrm{Ha}^{1}$, Sangbong $\mathrm{Yi}^{1}$, Jan Bohlen ${ }^{1}$, Xiaohua Zhou ${ }^{2}$, Heinz-Günter Brokmeier ${ }^{2}$, Norbert Schell ${ }^{3}$, \\ Dietmar Letzig ${ }^{1}$, Karl Ulrich Kainer ${ }^{1}$
}

\author{
${ }^{1}$ Magesium Innovation Centre, Helmholtz-Zentrum Geesthacht, Max-Planck Str. 1, 21502 Geesthacht, Germany \\ ${ }^{2}$ Institute of Materials Science \& Engineering, TU Clausthal, Agricolastr. 6, 38678 Clausthal-Zellerfeld, Germany \\ ${ }^{3}$ HZG Outstation at DESY, Helmholtz-Zentrum Geesthacht, Notkestr. 85, 22607 Hamburg, Germany
}

Keyword: Mg-Zn-RE alloy, deformation and recrystallization mechanisms, in-situ measurement, EBSD

\begin{abstract}
Many studies have shown that textures with less distinct alignment of basal planes and the related improvement of formability are found in alloys that contain rare-earth (RE) elements and zinc. However, the effect of the combination of these additional elements on the texture modification has not been yet clearly understood. In this work, sheet samples from $\mathrm{Mg}-\mathrm{Zn}$-RE alloys rolled at $400^{\circ} \mathrm{C}$ were used for in-situ synchrotron $\mathrm{X}$-rays diffraction measurements under tensile loading at different temperatures, in order to track the development of diffraction profiles and textures during deformation. In Mg-Zn-RE alloys, a significantly retardation of recovery and dynamic recrystallization during the high temperature deformation is observed in comparison to the RE-free $\mathrm{Mg}-\mathrm{Zn}$ alloy. The differences in the active deformation mechanisms as well as the dynamic recrystallization mechanisms are reviewed with respect to the texture alteration. For discussion of the impact of different mechanisms, EBSD observations reveal the microstructure development.
\end{abstract}

\section{Introduction}

Conventional Mg-based sheet alloys such as AZ31, with strong basal type textures, have been investigated in many studies in order to evolve potential for the limited sheet formability by restricted activities of slip systems. To improve the formability of $\mathrm{Mg}$ sheet, it is required to develop weaker textures, especially a less distinct alignment of basal planes parallel to the sheet plane. Texture weakening has been revealed in $\mathrm{Mg}$ alloy containing yttrium $(\mathrm{Y})$, cerium $(\mathrm{Ce})$, or neodymium $(\mathrm{Nd})$, i.e. rare earth (RE) elements, during rolling. It is reported that their addition in binary Mg-RE or ternary $\mathrm{Mg}-\mathrm{Zn}-\mathrm{RE}$ alloys contribute to higher accommodation of deformation by active basal $<\mathrm{a}>$ slip [1-4]. Furthermore, several studies have shown that texture weakening contributes to the activation of various deformation mechanisms, e.g. the formation of different twin types, shear bands, and the activation of $<\mathrm{c}+\mathrm{a}>$ slip, which also leads to an improvement of the formability $[1,5,6]$. However, it is also noted that such a texture modification is caused by the same various slip modes, shear bands, and different twin types during sheet rolling $[1,2]$. In the case of alloy ZE10, varied texture developments could be achieved by only small changes in the alloy composition and the application of different processing methods [3, 7]. Such effects still lack fundamental understanding and the effect of element concentration changes needs to be related to the activity of deformation and recrystallization mechanisms. Synchrotron X-ray radiation with short exposure time by transmission technique allows to analyze the properties of materials, as well as microstructure information [8]. Electron backscatter diffraction (EBSD) measurement allows the analysis of the microstructure development $[2,5,6,9]$. In this work, both techniques are used to reveal the differences in the deformation and recrystallization behavior on microstructure development of two magnesium sheet alloys during tensile deformation.

\section{Experimental procedures}

Two Mg alloys, Z2 and ZE21 as a RE containing counterpart, were machined in form of slab for rolling experiment after gravity casting of rectangular samples. The alloy composition and the homogenization heat treatment prior to rolling are listed in Table 1. A 50 ton laboratory rolling stand with cold rolls was used for rolling plates. The geometry of rolling slabs was $200 \times 100 \times 20 \mathrm{~mm}^{3}$. The rolling experiments were conducted with increasing degree of deformation per pass, 3 passes of 0.1 followed by 3 passes of 0.2 on Z2 and 4 passes of 0.1 followed by 3 passes 0.15 on ZE21. Different

Table 1. Chemical composition in wt. \% and experimental information of the examined alloys.

\begin{tabular}{llllllll}
\hline Alloy & $\begin{array}{l}\mathrm{Zn} \\
(\text { wt. } \%)\end{array}$ & $\mathrm{Ce}$ & $\mathrm{Mg}$ & $\begin{array}{l}\text { Homo- } \\
\text { genization }\end{array}$ & $\begin{array}{l}\text { Final thickness } \\
(\mathrm{mm})\end{array}$ & $\begin{array}{l}\text { Annealing } \\
\text { condition }\end{array}$ & $\begin{array}{l}\text { Average } \\
\text { grain size }(\mu \mathrm{m})\end{array}$ \\
\hline $\mathrm{Z} 2$ & 1.87 & - & Bal. & $20 \mathrm{~h}$ at $400^{\circ} \mathrm{C}$ & 8.25 & 10 min. at $385^{\circ} \mathrm{C}$ & 33 \\
ZE21 & 1.97 & 1.13 & Bal. & $16 \mathrm{~h}$ at $450^{\circ} \mathrm{C}$ & 7.95 & 20 min. at $350^{\circ} \mathrm{C}$ & 30 \\
\hline
\end{tabular}



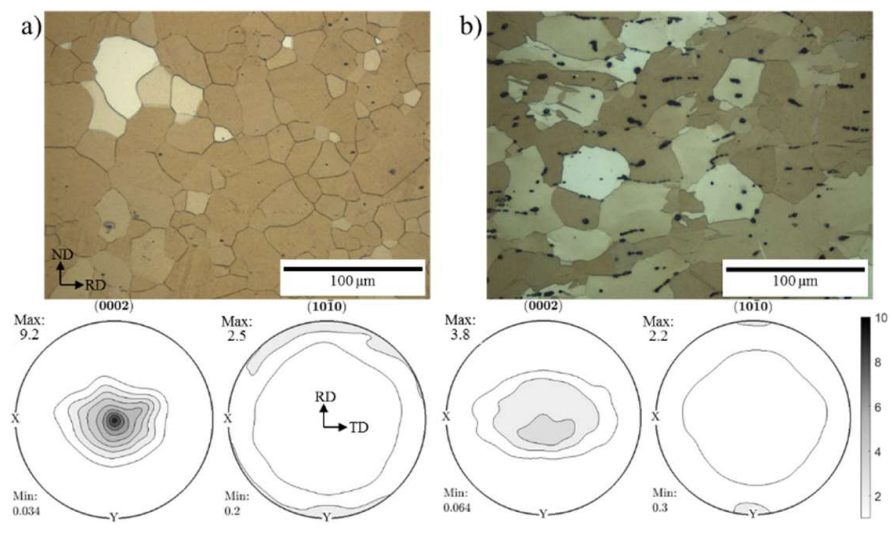

Fig. 1 Annealed microstructure and texture of the 2 sheets, (a) Z2 and (b) ZE21 alloy, prior to mechanical testing.

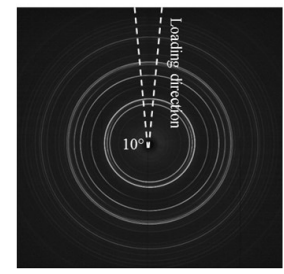

Fig. 2 Debye-Scherrer pattern of the tensile sample and sketch of the integrated sector along the LD. rolling temperatures were applied, $400^{\circ} \mathrm{C}$ for $\mathrm{Z} 2$ and $450^{\circ} \mathrm{C}$ for ZE21. After each rolling pass, the sheets were re-heated to the rolling temperature for $15 \mathrm{~min}$. The final gauge of the sheets was comparable at 7.95 $\mathrm{mm}$ and $8.25 \mathrm{~mm}$, respectively. After rolling, the sheets were annealed with different annealing conditions, in order to receive similar microstructures (Table 1), i.e. comparable grain sizes. The texture of the annealed sheets was measured using a Panalytical X-ray diffractometer and $\mathrm{Cu} \mathrm{K}_{\boldsymbol{\alpha}}$ radiation. The (10.0) and (00.2) pole figures were recalculated using a computer code MTEX [10]. The microstructure was observed by using standard metallographic sample preparation techniques and an etchant based on picric acid [11]. A universal testing machine was installed at the High Energy Material Science beamline, HEMS, P07B, at Petra III (DESY, Hamburg). In this work, a hard X-ray beam $(87 \mathrm{keV}, \lambda=0.1420 \AA)$ was chosen with beam size of $0.5 \times 0.5 \mathrm{~mm}^{2}$ and a sample detector distance of $1201 \mathrm{~mm}$ to investigate the texture development and the diffraction profiles during tensile testing. LaB6-powder has been used as standardization material. Tensile tests were performed using round tensile samples with $4 \mathrm{~mm}$ in diameter and $24 \mathrm{~mm}$ gauge length along the rolling direction (RD), at 3 temperatures, room temperature (R.T.), $100^{\circ} \mathrm{C}$, and $200^{\circ} \mathrm{C}$. The initial strain rate was $1 \times 10^{-4} / \mathrm{s}$. Texture measurement were repeated by using a fast PerkinElmer XRD 1621 detector during tensile loading at selected 5 points, $0.02,0.05,0.10$, 0.15 , and 0.20 strain. During texture measurements at R.T., the loading was stopped at each measuring point for texture measurement. In the case of measurement at $100^{\circ} \mathrm{C}$ and $200^{\circ} \mathrm{C}$, the strain rate was reduced to $2.9 \times 10^{-5} / \mathrm{s}$ to minimize stress relaxation. Sample rotation was applied for $105^{\circ}$ in $3^{\circ}$ steps for the texture measurements. DebyeScherrer patterns at each measuring point were collected to reveal the (10.0), (00.2), (10.1), (10.2), (11.0), and (10.3) reflections from the area detector using software Fit2D [12]. The pole figures and orientation distribution function (ODF) were recalculated using open source software MTEX [10]. Furthermore, a separate continuous experiment without stop or change in the strain rate has been carried out in order to collect the development of the diffraction profiles from in-situ diffraction profiles measurement. The initial strain rate was the same and no sample rotation was applied, keeping the normal direction (ND) of the sample parallel to the beam during loading. In order to evaluate diffraction profiles, the collected Debye-Scherrer patterns were integrated along loading direction (LD) with a sector of $10^{\circ}$, using Fit2D. Fig. 2 shows an exemplary Debye-Scherrer pattern. The integrated DebyeScherrer pattern allowed to reveal peak properties. The measured Full-width at half maximum (FWHM) was evaluated by using a modified Williamson-Hall plot (WH-plot) after instrumental and thickness correction using LaB6 powder [8]. The first 15 reflections were considered for calculating the dislocation density. The modified WH-plot uses the FWHM variation assuming that strain broadening is caused by dislocation [13]. In the present investigation, the following expression was used [8, 13]:

$$
\Delta \mathrm{K} \cong \gamma / \mathrm{D}+\left(\pi \mathrm{M}^{2} \mathrm{~b}^{2} / 2\right)^{1 / 2} \rho^{1 / 2} \mathrm{~K} \sqrt{\overline{\mathrm{C}}}+\mathrm{O}\left(\mathrm{K}^{2} \overline{\mathrm{C}}\right),
$$

where $\mathrm{D}$ is the coherently diffraction domain size, $\gamma$ equals to 0.9 when using FWHM in the analysis, $\rho$ and $b$ are the average dislocation density and the length of the Burgers vector of dislocations, respectively. $\Delta \mathrm{K}=\cos \Theta[\Delta(2 \Theta)] / \lambda$, where $\Delta(2 \theta)$ equals FWHM of the diffraction peak. $M$ is a dislocation arrangement parameter depending on the effective outer cut-off radius of dislocations. $\mathrm{O}$ is for a higher order term of $\mathrm{K}^{2} \overline{\mathrm{C}} . \overline{\mathrm{C}}$ is a contrast factor of dislocations [8, 13]. A more detailed introduction to the analysis can be found elsewhere $[8,13,14]$. In the case of hexagonal crystals, the contrast factor should be applied differently from cubic crystals because the hexagonal crystal has different types of slip system with different Burgers vectors. For the contrast factor of dislocation for hexagonal crystals, see details in $[15,16]$.

EBSD observations for tensile sample were prepared by electrochemical polishing using a Struers ${ }^{\mathrm{TM}}$ AC2 solution at $-25^{\circ} \mathrm{C}$. EBSD measurements were 
performed on the deformed area after 0.20 strain of tensile samples using a FE-SEM (Zeiss, Ultra 55), equipped with an EDAX ${ }^{\mathrm{TM}} / \mathrm{TSL}$ EBSD system with a Hikari detector. An accelerating voltage of $15 \mathrm{kV}$ was applied to scan an area of $250 \times 600 \mu \mathrm{m}^{2}$ with a step size of $0.6 \mu \mathrm{m}$. Evaluation was carried out using the TSL-OIM 7 analysis software. A clean-up procedure consisting of grain confidence index $(\mathrm{CI})$ standardization and a neighbor CI correlation was applied.

\section{Results and discussion}

The annealed microstructure and texture are shown in Fig. 1. A similar grain size of the 2 alloys was adjusted by different parameters of rolling and annealing. The average grain size of Z2 and ZE21 are $33 \mu \mathrm{m}$ and $30 \mu \mathrm{m}$, respectively (Table 1). However, the textures of the annealed sheets are different concurrent with the addition of $\mathrm{Ce}$ as a $\mathrm{RE}$ element [3]. After annealing, Z2 has a strong basaltype texture with $P_{\text {m.r.d. }}=9.2$, comparable to AZ31 as a conventional $\mathrm{Mg}$ alloy, while ZE21 has a weak basal texture $\left(\mathrm{P}_{\text {m.r.d. }}=3.8\right)$ and a spread of basal planes toward the transverse direction.

Stress-strain curves collected during the in-situ texture and diffraction profiles measurements are shown in Fig. 3. The stress relaxation is clearly visible at the texture measuring points. However, the stress-strain curves of the measurements for diffraction profiles of the same alloy are very similar so that the impact of stress relaxation on the texture development is neglected at this point. Z2 shows relatively low yield strength along $\mathrm{RD}$ at all temperatures in comparison with ZE21. Higher strain hardening is reached in Z2 than in ZE21 up to the ultimate tensile strength (UTS). Such a behavior has also been found in earlier work, corresponding to changed critically resolved shear stresses (CRSS) for individual slip system $[3,7]$.

Fig. 4 shows the pole figure after the tests $(\mathcal{E}=0.20)$. The (10.0) pole strengthens toward LD, while the (00.2) pole develops a transverse spread perpendicular to LD. The intensities of the (00.2) pole figure does not exhibit a clear tendency after the tests at 3 temperatures. The intensities of the (10.0) pole developed toward LD in both alloys and shows an increase after tests regardless on testing temperature. The significant differences between the
2 alloys are that the (00.2) pole of ZE21 alloy broadens clearly faster towards the TD than of Z2. Besides, the intensity of the (10.0) pole figure shows a different behavior in ZE21 compared to Z2 with increasing temperature. In Z2, there is no clear trend revealed with temperature after deformation. In ZE21, intensities are increasing with temperature, respectively. The broadening of the (00.2) pole as well as the intensity variation of the (10.0) pole can be related to a higher activation of prismatic $<a>$ slip in ZE21 than in Z2 with increasing temperature.

The diffraction profiles were evaluated by the slope of the modified WH-plot, in order to reveal the dislocation density changing through changes on individual property of peaks at selected strain points, i.e. FWHM variation. Fig. 5 shows an example of the modified WH-plot for the sample before loading and at UTS. The evaluation of the dislocation density of both alloys during tensile loading is shown in Fig. 6. The dislocation densities increase during tensile loading at RT in both alloys. However, $\mathrm{Z} 2$ shows faster relaxation of dislocation at $100^{\circ} \mathrm{C}$ and $200^{\circ} \mathrm{C}$ than ZE21. In other words, dislocation densities in $\mathrm{Z} 2$ seem to retain from the beginning in overall tendency, while dislocation densities in ZE21 increased tendencially during deformation at $100^{\circ} \mathrm{C}$ and $200^{\circ} \mathrm{C}$. The decreased dislocation density can be related to recovery (RV) and dynamic recrystallization (DRX) during microstructure development [17]. To compare the microstructure development after deformation, EBSD measurements were carried out using the same samples. The inverse pole figure (IPF) map, the grains with lower interior orientation spread (GOS) map, and misorientation histogram on the center of the samples after deformation $(\mathcal{E}=0.20)$ are presented in Fig. 7 for the experiments at 3 temperatures. In Z2, the IPF map at R.T. shows deformed grain and twins. Deformed grains are still visible after deformation at $100^{\circ} \mathrm{C}$, whereas the twins disappear. At $200^{\circ} \mathrm{C}$, locally deformed band or shear band are revealed, as indicated by white lines. The IPF map of ZE21 at R.T. shows also deformed grains and twins. However, at $100^{\circ} \mathrm{C}$ more distortional grains are found, corresponding to higher stored strain in the grains compared to Z2. At $200^{\circ} \mathrm{C}$, no shear bands are observed in ZE21. Such shear bands have been observed to accommodate the deformation in RE- free Mg alloy, e.g. AZ31. Such locally concentrated deformation leads to
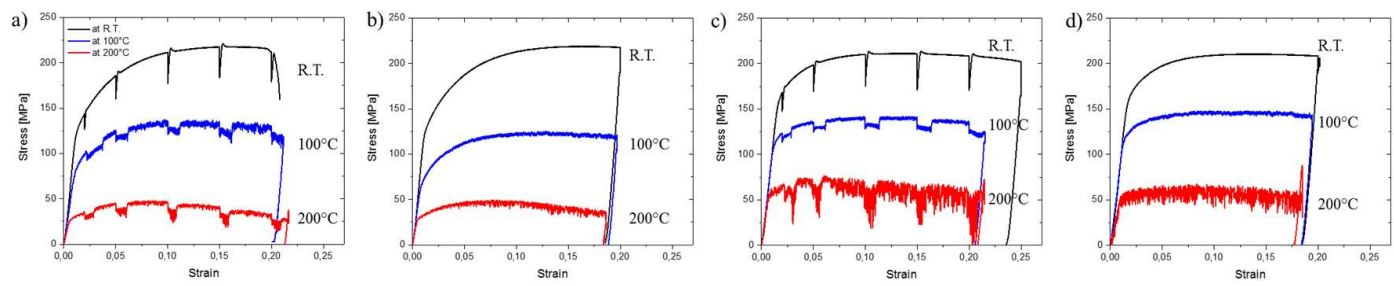

Fig. 3 Stress-strain curves for (a), (c) in-situ texture and (b), (d) diffraction measurements during tensile test along the RD in (a), (b) Z2 and (c), (d) ZE21 sheets. 


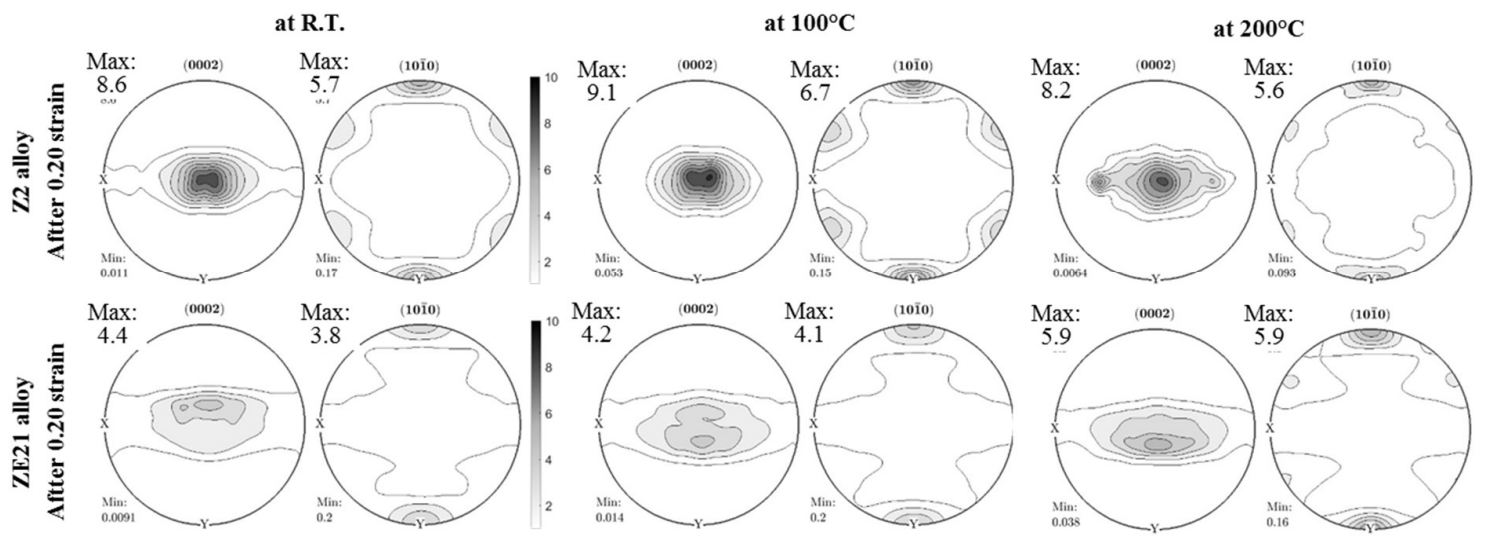

Fig. 4 Calculated pole figures of in-situ measurement after deformation $(\varepsilon=0.20)$ at 3 temperatures in the 2 alloys.

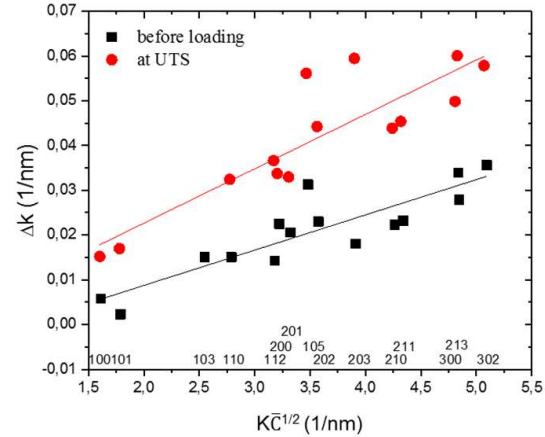

Fig. 5 An example of modified WH-plot before loading and at UTS on the ZE21 sheet.

inhomogeneous deformation [18]. Thus, there is a significant difference in the deformation and recrystallization behavior during tensile testing. To identify recrystallized grains, GOS maps are considered, assuming that recrystallized grains will appear with low orientation spread whereas nonrecrystallized deformed grains do not [19, 20]. Grains with GOS $<2^{\circ}$ and high angle grain boundaries (HAGB, $>15^{\circ}$ ) are considered. At R.T. and $100^{\circ} \mathrm{C}$, a very small amount of recrystallized grains is identified in both alloys.

Small grains recrystallized are only observed at $200^{\circ} \mathrm{C}$. In comparison, there are concentrated in the above mentioned bands in Z2 whereas in ZE21 they are preferentially found at grain boundaries. In Z2 the selected grains are larger compared to ZE21 indicating a growth restriction during recrystallization. In summary, only Z2 after deformation at $200^{\circ} \mathrm{C}$ exhibits a distinct fraction of recrystallized grains. Furthermore, misorientation angle histograms are shown which also help to reveal the deformation and recrystallization behavior [5, 9]. In case of Z2 at R.T., a pronounced peak is observed around $86^{\circ}$, resulting from a high amount of $\{1012\}$ tension twin boundaries after deformation. With increasing test temperature, recrystallized grains with peaks around $30^{\circ}$ in misorientation increase. Such peaks are related with recrystallization, with preferential rotation of $30^{\circ}$ around c-axis [21]. The increase of the fraction of such orientations seems to indicate the beginning of recrystallization between $\mathrm{R} . \mathrm{T}$. and $100^{\circ} \mathrm{C}$, which is not fully consistent with the finding of recrystallized grains in the GOS map. It is hypothesized that this is related to recovery of grains, which is also consistent with the decrease of the dislocation density in the WH-plot during deformation in Fig. 6. At $200^{\circ} \mathrm{C}$, recrystallized grains and misorientation peaks around $30^{\circ}$ can be related to DRX, with new grains concentrated along shear bands [17]. However, in case of ZE21, a clearly lower fraction of recrystallized grains is found. No evidence of the shear bands that played a role during recrystallization in $\mathrm{Z2}$ is found in this alloy. Recrystallized grains also remain smaller after testing at $200^{\circ} \mathrm{C}$ compared to $\mathrm{Z} 2$. The retarded recrystallization is also consistent with the misorientation histogram, where no distinct peak formation at $30^{\circ}$ misorientation is observed. However, peaks at misorientation lower than $15^{\circ}$ occur with increasing temperature. Such peaks are consistent with higher stored energy [9], associated with higher dislocation density or low angle grain boundaries (LAGB). This finding is also consistent with the result of modified WH-plot in Fig. 6. Thus, in ZE21 recrystallization appears retarded and leads to continuous increase of internal strain as well as the dislocation densities during testing even at $200^{\circ} \mathrm{C}$.

For DRXed grains in GOS map, in Z2, the new recrystallized grains are created along shear band [22], while they are created around grain boundary in ZE21. This difference in the nucleation of new grains may have an impact on the recrystallization kinetics as well. In summary, the addition of RE elements leads to a retardation of DRX, which in the RE-free alloy $\mathrm{Z} 2$ has been enhanced in shear band $[1,3,7]$. Also the decreasing intensity of the (10.0) pole between the tensile tests at $100^{\circ} \mathrm{C}$ and $200^{\circ} \mathrm{C}$ can be explained by a proposed enhancement of recrystallization along shear band and a resulting higher fraction of recrystallized grains at $200^{\circ} \mathrm{C}$ (Fig. 4). 

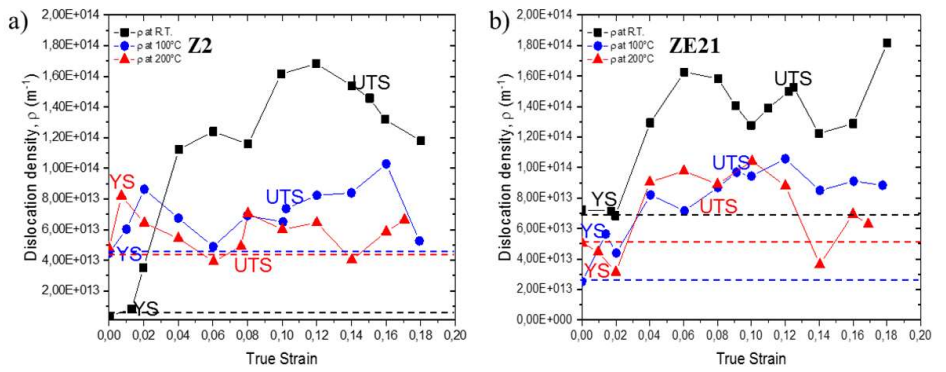

IPF at R.T.

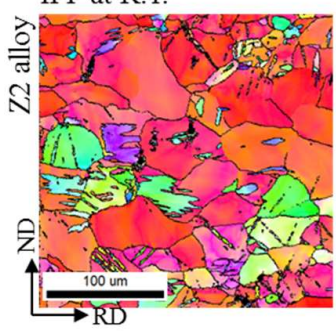

IPF at $100^{\circ} \mathrm{C}$

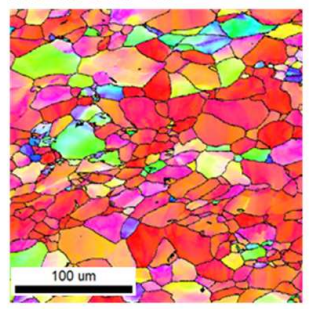

$\mathrm{GOS} \leqq 2^{\circ}$ at $100^{\circ} \mathrm{C}$.
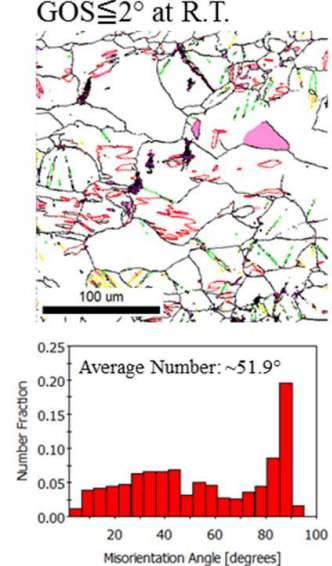

IPF at R.T.

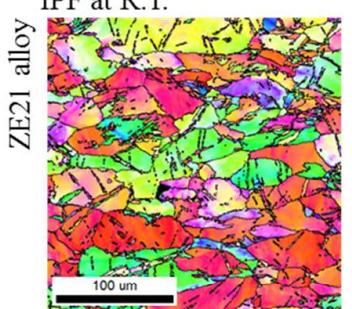

$\mathrm{GOS} \leqq 2^{\circ}$ at R.T.
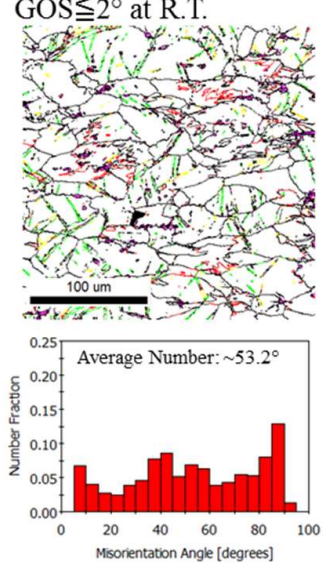
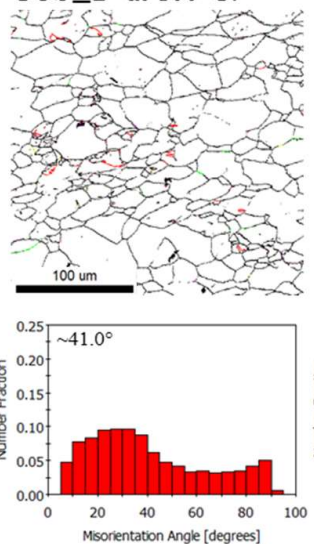

IPF at $100^{\circ} \mathrm{C}$

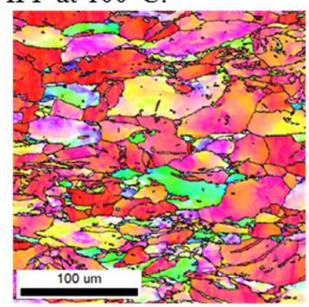

$\mathrm{GOS} \leqq 2^{\circ}$ at $100^{\circ} \mathrm{C}$.
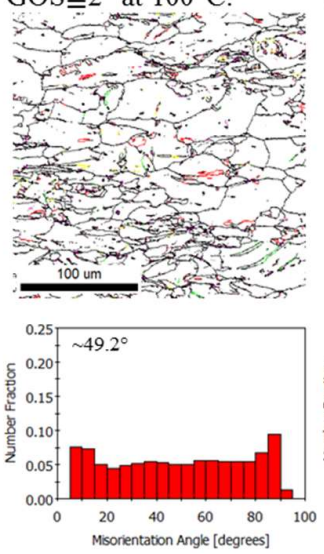

IPF at $200^{\circ} \mathrm{C}$.

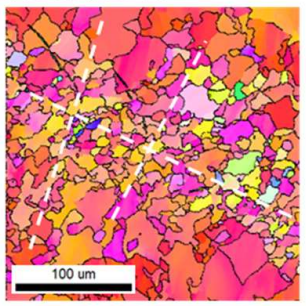

GOS $\leqq 2^{\circ}$ at $200^{\circ} \mathrm{C}$.
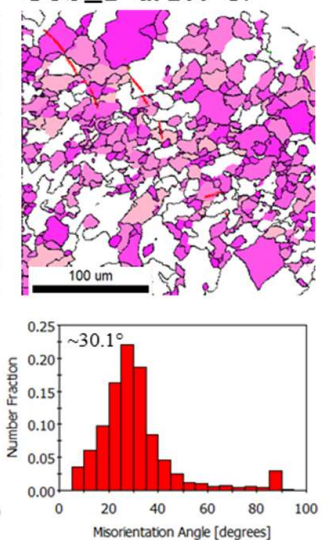

IPF at $200^{\circ} \mathrm{C}$.

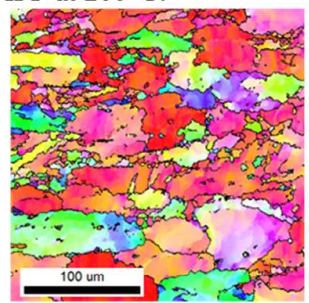

$\mathrm{GOS} \leqq 2^{\circ}$ at $200^{\circ} \mathrm{C}$.
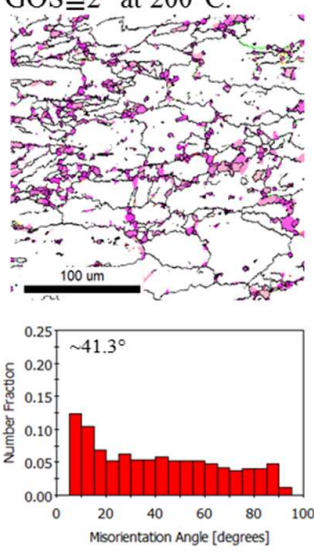

Fig. 6 Dislocation density variations of the (a) Z2 and (b) ZE21 at 3 temperatures during deformation.

Fig. 7 Sections of IPF maps, GOS maps with $\mathrm{HAGB}\left(>15^{\circ}\right)$, and respective misorientation histograms of EBSD measurement after deformation $(\varepsilon=0.20)$ at 3 temperatures;
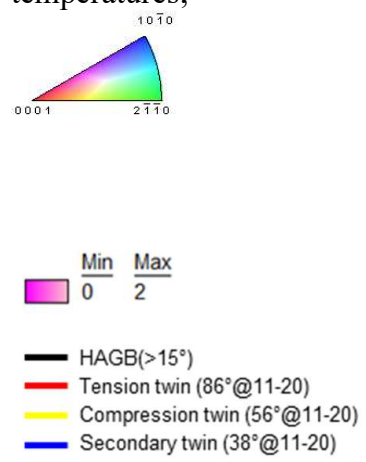


\section{Summary}

The microstructure development using in-situ synchrotron radiation measurement and EBSD measurement at 3 different temperatures of RE freeand RE elements containing $\mathrm{Mg}$ sheets was analyzed in the present study. In comparison with the Z2 alloy, a high activity of prismatic $<\mathrm{a}>$ slip has been revealed with increasing testing temperature, especially in case of ZE21, resulting in an intensity increase of the (10.0) component toward LD and the (00.2) spread perpendicular to LD. The visibility of this increasing activity of prismatic $<a>$ slip was reduced with the reformation of the microstructure due to enhanced recrystallization associated with a preferred shear band nucleation of grains in $\mathrm{Z} 2$ at $200^{\circ} \mathrm{C}$. The dislocation densities have been revealed by using a modified WH-plot which show a clear increase during deformation at R.T.. The dislocation densities in $\mathrm{Z} 2$ at $100^{\circ} \mathrm{C}$ and $200^{\circ} \mathrm{C}$ decreased due to $\mathrm{RV}$ and DRX during deformation.

\section{Acknowledgement}

The authors appreciate Mr. B. Schwebke and Mr. A. Reichart for technical supports during experiments as well as the DESY for the provision of beamtime and the facilities of Petra III (proposal. I-20150212 and I-20160228). This work has been financially supported by the Deutsche Forschungsgemeinschaft (Grants BO 2461/4-1, Yi 103/2-1, and BR 961/7-1).

\section{References}

1. K. Hantzsche et al. (2010) Effect of rare earth additions on microstructure and texture development of magnesium alloy sheets. Scripta Materialia 63:725-730

2. J. Bohlen et al. (2015) The Influence of the Combination of Alloying Elements on the Microstructure and Texture Development During Rolling and Annealing of Magnesium. Paper presented at the 10th International Conference, Mg 2015, Jeju, 11-16 October 2015

3. J. Bohlen et al. (2007) The texture and anisotropy of magnesium-zinc-rare earth alloy sheets. Acta Materialia 55:2101-2112

4. Y. Chino et al. (2011) Effects of Ca on Tensile Properties and Stretch Formability at Room Temperature in $\mathrm{Mg}-\mathrm{Zn}$ and $\mathrm{Mg}-\mathrm{Al}$ Alloys. Materials Transactions 52(7):1477-1482

5. D.W. Kim et al. (2013) Texture Evolution in MgZn-Ca Alloy Sheets. Metallurgical and Materials transactions A 44A:2950-2961.

6. S.B. Yi et al. (2010) Mechanical anisotropy and deep drawing behaviour of AZ31and ZE10 magnesium alloy sheets. Acta Materialia 58:592-605
7. L. Stutz et al. (2011) Influence of the processing of magnesium alloys AZ31 and ZE10 on the sheet formability at elevated temperature. Key Engineering Materials 473:335-342

8. Z.Y. Zhong et al. (2015) Dislocation density evolution of AA 7020-T6 investigated by in-situ synchrotron diffraction under tensile load. Materials Characterization 108:124-131

9. J. Victoria-Hernández et al. (2016) Straininduced selective grain growth in AZ31 Mg alloy sheet deformed by equal channel angular pressing. Materials Characterization 113:98-107

10. F. Bachmann et al. (2010) Texture Analysis with MTEX - Free and Open Source Software Toolbox. Solid State Phenom. 160:63-68.

11. V. Kree et al. (2004) The Metallographical Examination of Magnesium Alloys, Practival Metallography 41:233-245

12. A.P. Hammersley (1998) FIT2D V12.012 Reference Manual V6.0 ESRF98HA01T. ESRF Internal Report. Accessed 8 August 2017

13. T. Ungár et al. (2001) Densities and character of dislocations and size-distribution of subgrains in deformed metals by X-ray diffraction profile analysis. Mater. Sci. Eng. A 319-321:274-278

14. T. Ungár et al. (2001) Crystallite size distribution and dislocation structure determined by diffraction profile analysis: principles and practical application to cubic and hexagonal crystals. J. Appl. Crystallogr. 34:298-310

15. K. Máthis et al. (2004) The evolution of nonbasal dislocations as a function of deformation temperature in pure magnesium determined by X-ray diffraction. Acta Materialia 52:2889-2894

16. I.C. Dragomir et al. (2002) Contrast factors of dislocations in the hexagonal crystal system. J. Appl. Cryst. 35:556-564

17. T. Ungár (2004) Microstructural parameters from X-ray diffraction peak broadening. Scripta Materialia 51:777-781

18. M.R. Barnett et al. (2007) Influence of microstructure on strain distribution in Mg-3AlZn. Scripta Materialia 57(12):1125-1128

19. J. Victoria-Hernandez et al. (2014) The influence of the recrystallization mechanisms and grain growth on the texture of a hot rolled AZ31 sheet during subsequent isochronal annealing. Journal of Alloys and Compounds 616:189-197

20. J. Bohlen et al. (2015) Calcium and zirconium as texture modifiers during rolling and annealing of magnesium-zinc alloys. Materials Characterization 101:144-152

21. N. Bozzolo et al. (2002) Recrystallization Textures in some Hexagonal Alloys. Materials Science Forum 408-412:901-906.

22. A. Galiyev et al. (2001) Correlation of plastic deformation and dynamic recrystallization in magnesium alloy ZK60. Acta mater. 49:11991207 